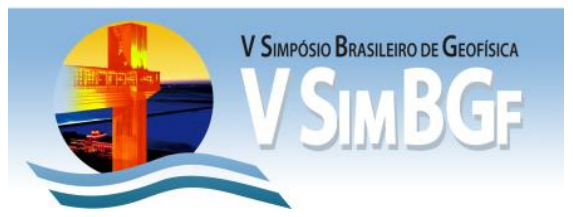

\title{
Integração dos métodos de Gpr, Eletrorresistividade e do EM-34 na estimação da distribuição espacial de aquíferos rasos no município de Cabo Frio/RJ
}

\author{
Alex Muniz Rodrigues* ${ }^{*}$ - alex07rodrigues@gmail.com \\ Alan Freitas Machado ${ }^{1}$; Emin Ugur Ulugergerli. ${ }^{2}$ \\ ${ }^{1}$ Instituto de Física, UERJ; ' ${ }^{2}$ epartment of Geophysical Engineering. ÇOMU, Turkey
}

\section{Copyright 2012, SBGf - Sociedade Brasileira de Geofísica}

Este texto foi preparado para a apresentação no V Simpósio Brasileiro de Geofísica, Salvador, 27 a 29 de novembro de 2012. Seu conteúdo foi revisado pelo Comitê Técnico do V SimBGf, mas não necessariamente representa a opinião da SBGf ou de seus associados. É proibida a reprodução total ou parcial deste material para propósitos comerciais sem prévia autorização da SBGf.

\section{Abstract}

The present work focuses on determination of underground aquifers in the region of the Municipal Ecological Park Mico Leão Dourado (located in the River Basin São João drainage area which has aproximatelly $2,190 \mathrm{~km}^{2}$, which includes the area (189 $\mathrm{km}^{2}$ ) of flat topography of Cabo Frio). The objective is to generate technical information to assist the Municipality of Cabo Frio and government agencies to use water wisely for the eventual supply of urban communities and enterprises to improve with the Municipal Ecological Park of the Mico Leão Dourado. Tamoio district, region of Cabo Frio, and training of staff in the use of methodologies and tools of exploration geophysics.

\section{Introdução}

A área do Parque Ecológico Municipal do Mico Leão Dourado do Município de Cabo Frio está situada na Bacia Hidrográfica do Rio São João que possui área de drenagem em torno de $2.190 \mathrm{~km}^{2}$, onde se insere a área de Cabo Frio $\left(189 \mathrm{~km}^{2}\right.$ ) (Costa, 1999) de topografia plana.

A água subterrânea desempenha um papel vital para a população do estado do Rio de Janeiro de modo geral, sendo que a sua escassez ou o aumento da exploração, é mais acentuada em regiões de urbanização crescente e desordenada. Esse fator é bem evidente na Região dos Lagos, Niterói e Baixada Fluminense. Outro fator que ainda é observado é com relação à atitude generalizada de subestimar os riscos de contaminação ou poluição das águas subterrâneas, o que justifica conhecer o substrato e a estrutura dos pacotes de sedimentos que podem conter aquíferos confinados. De certa forma, não se pode ignorar a necessidade crescente de estudos relativos ao uso e proteção dos recursos hídricos como um fator de desenvolvimento sustentável das atividades humanas e da qualidade ambiental.

A parceria entre a prefeitura de Cabo Frio e a Universidade do Estado do Rio de Janeiro (UERJ), se insere no âmbito de formação de recursos humanos e ao mesmo tempo na geração de informações, técnicas com ferramentas de investigação em sub superfície de modo a contribuir com o enriquecimento do banco de dados da referida área.

\section{Metodologia/ Problema Investigado}

Os métodos usados foram a eletrorresistividade, o EM-34 e o GPR. A eletrorresistividade consiste de medidas de impedância, com subsequente interpretação em termos de propriedade elétrica da estruturação geológica em sub superfície, baseado na resposta de cada material ao fluxo de uma corrente elétrica. Foram realizadas 8 sondagens elétricas (Arranjo Schlumberger) expandindo os eletrodos de corrente até $150 \mathrm{~m}$, em cada estação, onde a densidade populacional é maior, ainda que esta área esteja dentro do parque. Informações geológicas apontam que essa área havia sido desmatada e sem nenhuma intervenção do tipo despejo de entulhos ou material estranho ao local. Sendo assim, tudo indica que os resultados refletem a real situação do meio. Os dados de Eletrorresistividade foram processados e invertidos em duas dimensões (2D) com o programa de Sondagem Elétrica (SE) desenvolvido por Ulugergerli, 2006. Este programa permitiu estimar o nível freático em alguns pontos de investigação foram observados de modo claro. Já o EM-34 consiste na leitura da condutividade elétrica do material devido aos campos eletromagnéticos gerados pela bobina emissora e pela anomalia encontrada. Onde a bobina que é dita emissora, é responsável pela geração do campo magnético primário, esse campo magnético induz uma corrente elétrica no material rochoso, este gera um campo magnético secundário devido à corrente induzida. A segunda bobina é dita receptora, pois é ela que fará a leitura dos campos magnéticos primários e secundários. Com as leituras dos dois campos magnéticos é determinada a condutividade aparente do meio encontrado. Usamos uma separação de 10, 20 e $40 \mathrm{~m}$ de separação entre as bobinas transmissora e a receptora. Estes valores são invertidos usando aproximação 1D em cada ponto de leitura e os resultados têm formado uma seção pseudo $2 \mathrm{D}$ da área de pesquisada. A análise hidrológica e sedimentar foi realizada a partir das seções de GPR, os dados de GPR foram obtidos com uma antena de $100 \mathrm{MHz}$ (Ramac/Mala). 


\section{Resultados}

A Eletrorresistividade mostrou a presença de alteração no solo, seguido de uma camada mais compacta e, por fim, uma camada onde a resistividade cresceu bastante, provavelmente devido à presença de uma rocha dura. $\mathrm{O}$ nível freático foi identificado a uma profundidade variável, estando entre 5 e 7 metros. A configuração indica a existência de episódios de deposição sedimentar com intervalos curtos de tempo e marcados pela deposição de fácies arenosas mais espessas. O compartimento propicia a existência de níveis d'água suspensos devido à existência de camadas lamosas finas intercaladas a camadas arenosas.

Após o tratamento dos dados da eletrorresistividade fazendo a inversão em 2D (Figura 1) podemos constatar que esse método detectou algumas anomalias com resistividade pequena dentro do intervalo da resistividade da água e em profundidades menores do que $20 \mathrm{~m}$.

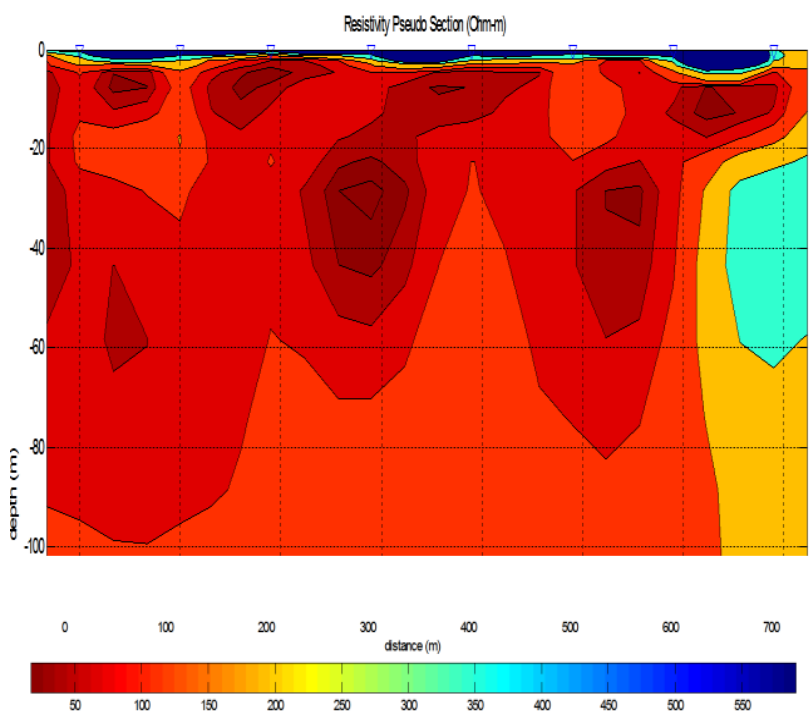

Figura 1 - Inversão 2D dos dados da eletrorresistividade

O EM-34 mostrou contrastes de condutividade em uma profundidade inferior do que $20 \mathrm{~m}$ e essa anomalia detectada apresenta uma condutividade muito elevada que está dentro da faixa de valores encontrada para a água. Ou seja, como a condutividade e a resistividade são grandezas físicas inversas as suas propriedades físicas são opostas como podemos observar nas figuras 1 e 2. Quando a resistividade é pequena (figura 1) na condutividade é elevada (figura 2) Como era esperado para as propriedades elétricas da água.

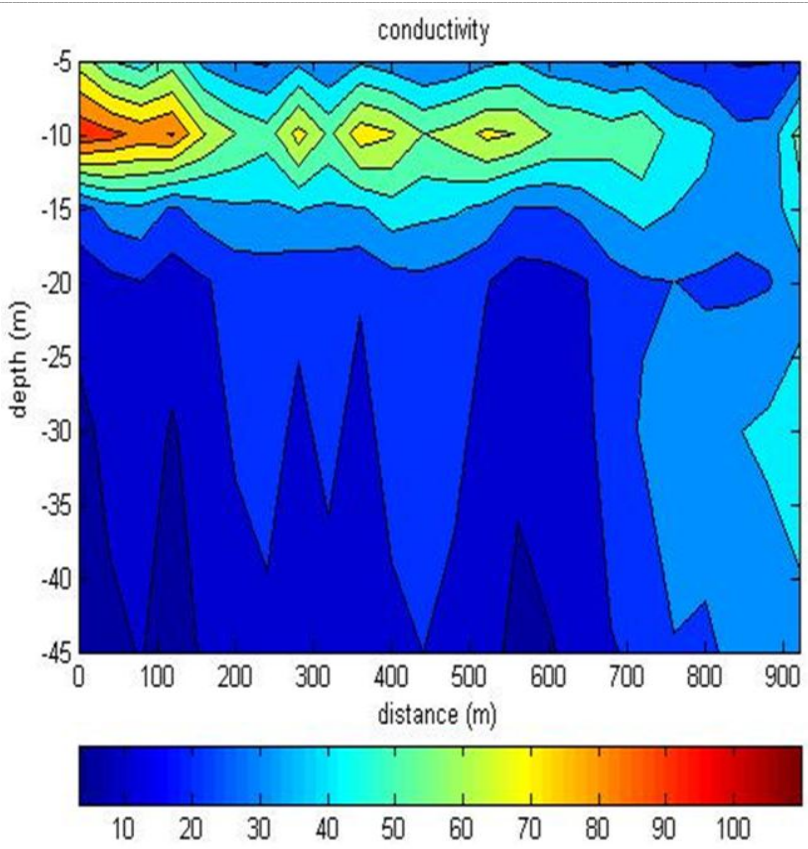

Figura 2 - Inversão 2D dos dados de condutividade

Já a seção de GPR comprovam as alterações nas sub camadas possibilitando a existência de aquíferos confinados, como mostra a figura 3. As seções GPR podem ser subdivididas em dois compartimentos: o primeiro representado por uma camada superior que foi interpretada como proveniente do solo de alteração local, e possivelmente dos depósitos quaternários da região e, um segundo, com acamamento sobreposto, sugerindo deposição sedimentar em várias etapas, com uma inclinação de aproximadamente $30^{\circ}$, na direção $\mathrm{E}-\mathrm{W}$.

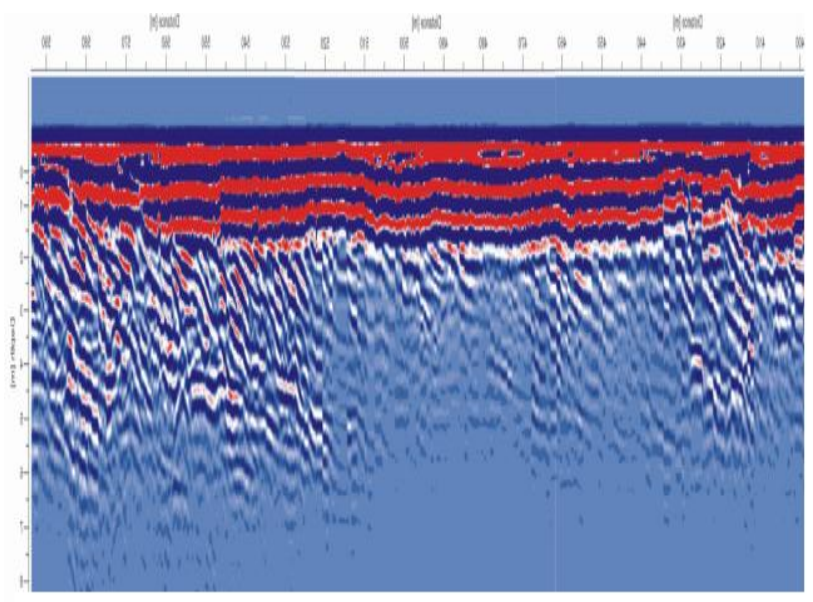

Figura 3 - Seção 2D de GPR 


\section{Discussão e Conclusões}

Com os fatos apresentados no decorrer do trabalho mostram que o método da eletrorresistividade mostrou a presença de alteração no solo, seguido de uma camada mais compacta e por fim uma camada onde a resistividade foi bastante acentuada, contudo apenas com esse método não podemos inferir a existência ou não de aquíferos rasos na região para melhor consistência a caracterização de águas subterrâneas utilizamos, mas dois métodos. O GPR confirma a divisão entre as camadas confirmando as diferenças de resistividades detectadas pela eletrorresistividade. Por sua vez o método magnético também detecta diferenças de condutividades entre as camadas indicadas pelo GPR. Ou seja, a eletrorresistividade e o EM-34 possivelmente estão indicando anomalias que possuem propriedades físicas equivalentes ao da água provavelmente correspondem a aquíferos confinados.

\section{Agradecimentos}

A prefeitura de Cabo Frio.

\section{Referências}

ANNAN, A. P. (1992) Use and techniques of GPR in near surface geophysics. Society of Exploration Geophysicists. Workshop Notes, Sensor \& Software Inc. $110 p$

Costa, H. 1999. Subsídios para gestão dos recursos hídricos das bacias hidrográficas dos rios Macacu, São João, Macaé e Macabu. Projeto Planagua SEMADS/GTZ de Cooperação Brasil-Alemanha, 284p.

FEEMA. 1988. Fundação Estadual de Engenharia e Meio Ambiente. Perfil Ambiental do Município de Cabo Frio. Rio de Janeiro, 52p.

RADPRO (1996) Manual do software de processamento de dados do GPR RAMAC na versão 2.25. MaläGeoscience. 52p

Ulugergerli, E.U 2006. Users manual for DC2D and software documentation for two-dimensional inversion of DC sounding data: Onsekizmart University, Department of Geophysics Engineering, Terzioglu Yerleşkesi, Çanakkale, 17020, Turkey.

WARD, S. H., 1990, Resistivity and induced polarization methods: in Geotechnical and Environmental Geophysics, Vol. 1, Ward, S. H., ed: Society of Exploration Geophysicists. 
Integração dos métodos de Gpr, Eletrorresistividade e do EM-34 na estimação da distribuição espacial de aquíferos rasos 4 no município de Cabo Frio/RJ

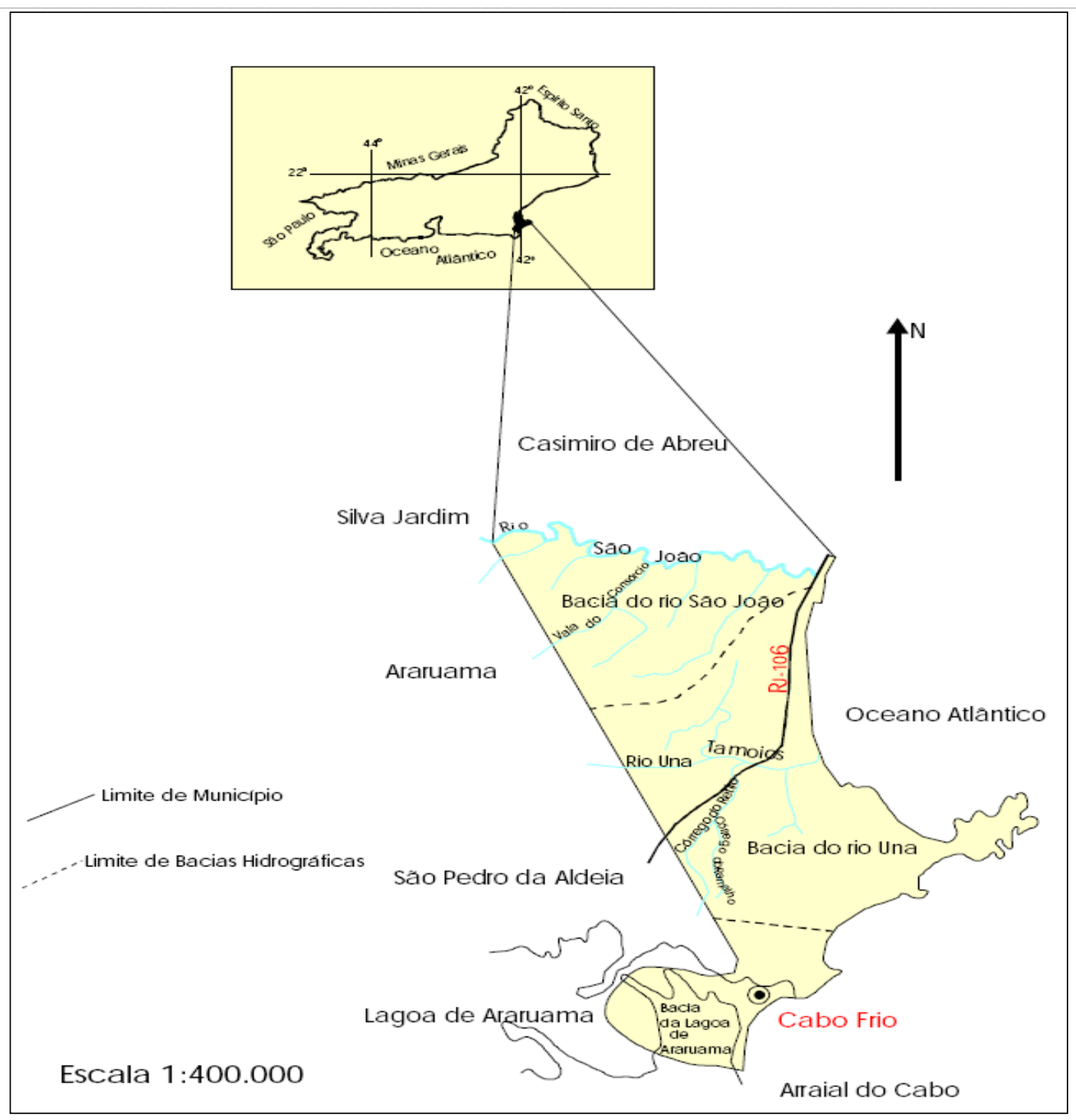

Figura 4 - Mapa de localização do Município de Cabo Frio apresentando as principais bacias hidrográficas e os municípios limítrofes (FEEMA 1988). Local onde os perfis de GPR + EM + Eletrorresistividade foram usados. 